\title{
Adolescent risk-taking and social influence in the context of exploration
}

\author{
Simon Ciranka ${ }^{1,2 *}$, Wouter van den Bos ${ }^{1,2,3}$ \\ ${ }^{1}$ Max Planck Institute for Human Development, Center for Adaptive Rationality, Berlin, Germany \\ ${ }^{2}$ Max Planck UCL Centre for Computational Psychiatry and Ageing Research, Berlin, Germany \\ ${ }^{3}$ Department of Developmental Psychology, University of Amsterdam, The Netherlands
}

\section{Funding}

S.C. is a pre-doctoral fellow of the International Max Planck Research School on Computational Methods in Psychiatry and Ageing Research (IMPRS COMP2PSYCH). The participating institutions are the Max Planck Institute for Human Development, Berlin, Germany, and University College London, London, UK.

WB is supported by the Open Research Area (ID 176), the Jacobs Foundation, the European Research Council (ERC-2018-StG-803338) and the Netherlands Organization for Scientific Research (NWOVIDI016.Vidi.185.068)

\section{Author Contributions}

Simon Ciranka: Conceptualization, methodology, software, visualization, writing- original draft, writing- editing. Wouter van den Bos: Conceptualization, writing- original draft, writing- editing, supervision.

\section{* Correspondence:}

Corresponding Author: Simon Ciranka

Ciranka@mpib.berlin.mpg.de

Keywords: Adolescence, Social Influence, Risk-Taking, Agent-Based Modelling, Exploration. 


\section{Abstract}

Adolescents are often described as a strange and different species that behaves like no other age group, typical behaviours being excessive risk-taking and sensitivity to peer influence. Different theories of adolescent behaviour attribute this to different internal mechanisms like undeveloped cognitive control, higher sensation-seeking or extraordinary social motivation. Many agree that some of adolescent risk-taking behaviour is adaptive. Here we argue that to understand adolescent risktaking, and why it may be adaptive, research needs to pay attention to the adolescent environments' structure and view adolescents as learning and exploring agents in it. We identify three unique aspects of the adolescent environment: 1) the opportunities to take risks are increased significantly, 2) these opportunities are novel and their outcomes uncertain, and 3) peers become more important. Next, we illustrate how adolescent risk-taking may emerge from learning using agent-based modelling, and show that a typical inverted-U shape in risk-taking may emerge in absence of a specific adolescent motivational drive for sensation-seeking or sensitivity to social information. The simulations also show how risky exploration may be necessary for adolescents to gain long-term benefits in later developmental stages and that social learning can help reduce losses. Finally, we discuss how a renewed ecological perspective and the focus on adolescents as learning agents may shift the interpretation of current findings and inspire future studies. 


\section{Introduction}

A time-honoured view of adolescence is that as a period of trials and tribulations (Sturm und Drang) on the way to adulthood (Hall, 1904). Consistent with this view, adolescence is associated with a peak in risky behaviours such as reckless driving, crime, binge drinking, unprotected sex, and experimenting with drugs (Gullone et al., 2000; Johnston et al., 2014; Shulman et al., 2013; Steinberg et al., 2018). Typically, these behaviours occur in the presence or presumed influence of peers (Albert et al., 2013; Monahan et al., 2009; van Duijvenvoorde et al., 2016). Although it is often stressed that while adolescent risk-taking has detrimental side-effects, part of these behaviours may serve some adaptive function, how exactly, however, remains unclear. Here we argue that if we aim to understand how risk-taking and peer influence can be adaptive, we need to (1) put more emphasis on understanding the interaction between learning, exploration and risk behaviour, and (2) better understand the interaction between adolescents and their environment. The first point builds on the idea that taking a risk can lead to meaningful experiences that will be beneficial in a later developmental stage (Romer et al., 2017; van den Bos et al., 2019). The second point is vital because behaviour can only be adaptive in relation to the environment in which it occurs (Simon, 1956). We believe that such a broader perspective will enrich the general understanding of adolescent behaviour. We begin by reviewing how risk-taking is defined in the adolescent literature, indicating a distinction between impulsive and planned risk-taking, and a shift of focus from merely harmful behaviour to one on exploration and learning. Next, we identify some key factors that characterize the environment which adolescents have to explore. Finally, we implement such an environment and run an agent-based learning model providing evidence that "typical" adolescent peak in risky behaviour may emerge from the interaction of an exploring agent and the environment in the absence of adolescent-specific motivational drives for reward or social feedback. In addition, our simulations indicate that under certain circumstances, both risk-taking and social influence can have long-term benefits, even though there are also negative outcomes in the short term.

\section{Risk, uncertainty and exploration}

Risk-taking does not refer to a well-defined set of actions (Frey et al., 2017). Risk-taking is also not necessarily illegal or dangerous. Instead, taking a risk is taking an action for which the outcome is uncertain, and potential consequences can be both, beneficial or harmful (Duell \& Steinberg, 2019; Hertwig et al., 2019; Duell \& Steinberg, this issue). At least two types of risk-taking can be distinguished based on their differences in underlying motivational mechanisms. The first type, reactive risk, explains adolescent risk behaviour due to the combination between poor response inhibition and increased reward sensitivity (Rosenbaum et al., 2018; Shulman et al., 2016; Steinberg, 2008). 
According to several adolescent risk-taking frameworks, this mismatch is due to an adolescent-specific imbalance between neural systems that support cognitive control and those that support reward processing (Ernst et al., 2005; Luna et al., 2013; Shulman et al., 2016). Although there is no doubt that some of the typical reckless adolescent behaviour falls in this category, and that this can lead to some undesirable outcomes, more recently it has been suggested that a significant proportion of adolescent behaviour comprises reasoned risk behaviour. Reasoned risk is strategic, planned well in advance, and relies on increasing cognitive control capacity in combination with an increased drive towards sensation seeking (Romer et al., 2017). Along these lines, a recent study reported that risk behaviour was associated not only with higher levels of sensation seeking but also with better working memory and greater future orientation (Maslowsky et al., 2019).

Furthermore, other studies have shown that adolescent risk engagement like binge drinking is strongly negatively correlated with their risk-perception (Ciranka \& van den Bos, in press; Johnston et al., 2014), suggesting that adolescents consider costs and benefits before engaging in risky behaviour. What unites many current theories of adolescent risk behaviour is the assumption that it can be adaptive. It is hypothesized that taking a risk can generate meaningful experiences enabling adolescents to interact with their future environment beneficially, and help adolescents to explore and learn about the world and themselves (Crone \& Dahl, 2012; Rodman et al., 2017; Romer et al., 2017; Telzer, 2016; van den Bos et al., 2019; Worthman \& Trang, 2018). Indeed, the adaptive potential of adolescent risk-taking behaviour becomes apparent when considering the developmental tasks and environment which adolescents are facing. Adolescents have to learn how to set up an independent household, become economically self-sufficient, emotionally stable, find their place in novel peer groups, build their own identity and eventually establishing a family unit of their own. In other words, adolescents developmental task is to become an independent adult (Nelson et al., 2016). On the way to adulthood, adolescents could hardly succeed if they would not take the risk to "leave their nest" (Bowers \& Natterson-Horowitz, 2020). Such a notion dovetails with the general definition of risktaking as "taking an action where outcomes are uncertain and could both be harmful or beneficial". As such, part of adolescent risk-taking might be re-cast, from simply doing something potentially harmful to a more goal-directed act of exploration. Taking the risk to explore novel environments may lead adolescents to discover new niches and learn about novel opportunities (Sercombe, 2014; Willoughby et al., 2013). This perspective also suggests that when a child enters the world of adolescence, and much is unknown, exploration has high benefits, but these benefits will inevitably decline as a function of learning. In other words, exploration-based risk-taking will introduce a sudden increase in risk-taking that decreases again towards adulthood leading to an adolescent peak in risky behaviour. 


\section{Peer influence and social learning}

The adolescent peak in risk-taking is often attributed to an adolescent-specific response to their peers. Some theories emphasize that peer presence is especially arousing for adolescents (Gardner \& Steinberg, 2005). This arousal leads adolescents to focus on rewards, resulting in impulsive decisions and risk-taking (Albert et al., 2013; Shulman et al., 2016). For instance, some studies suggest that the general arousal associated with peer presence makes adolescents drive riskier in a driving simulation (Chein et al., 2011; Gardner \& Steinberg, 2005). On the other hand, adolescents may only show increased risk-taking behaviour when they believe that their peers expect them to drive aggressively - suggesting a form of reasoned risk-taking (Blakemore \& Mills, 2014; Romer et al., 2014). According to this view, peer influence is more in line with planned risk-taking because it might be the result of a cost-benefit analysis in which one specifically considers the social benefits, for instance gaining status or belonging to a group (Blakemore \& Mills, 2014; Cialdini \& Goldstein, 2004; Ciranka \& van den Bos, 2019; Yeager et al., 2018).

Yet there is a third perspective toward social influence, currently underrepresented in the adolescent literature: social influence comprises social learning which can increase ones' confidence about how to make decisions in a complex and uncertain environment (FeldmanHall \& Shenhav, 2019; Gigerenzer \& Gaissmaier, 2011; Morgan \& Laland, 2012; Morgan et al., 2015; Toelch \& Dolan, 2015). For instance, observing others may entail information about which actions are more or less likely to lead to rewards. When faced with a novel and uncertain environment, adopting others' behaviour can be beneficial (Chase et al., 1998; Mehlhorn et al., 2015) because it protects the individual from potentially costly trial and error learning (FeldmanHall et al., 2017; Molleman et al., 2014, 2019). Several empirical studies have shown that when people are more uncertain, they use social information more (Behrens et al., 2008; Biele et al., 2011; Ciranka \& van den Bos, 2020; Toyokawa et al., 2019). From a developmental perspective, this suggests that a life phase associated with novelty and uncertainty, like adolescence, will also be associated with more social information use.

\section{Learning and the environment}

To date, learning and experience do not play a significant role in many existing theories on adolescent risk-taking. Exceptions are fuzzy trace theory (Rivers et al., 2008) and the Life Span Wisdom Model (Romer et al., 2017). However, both are neither explicit nor formal models of learning. A formalism would aid in generating expectations about how experience and knowledge will impact future behaviour and how a normative learning process might look like across development.

To further our intuitions about how risky behaviour, specifically its developmental rise and fall, may emerge from the interaction between adolescents and their environment, we turn to the formal 
framework of reinforcement learning (Sutton \& Barto, 2018). A reinforcement learning agent must learn to make good decisions in an uncertain environment by interacting with it (Collins \& Cockburn, 2020), much like adolescents do (Davidow et al., 2018). Good decisions are those that reap the most long-term rewards for the agent in a given environment. Eventually, the agents' behaviour will be optimally adapted to their experience with their environment (figure 1).

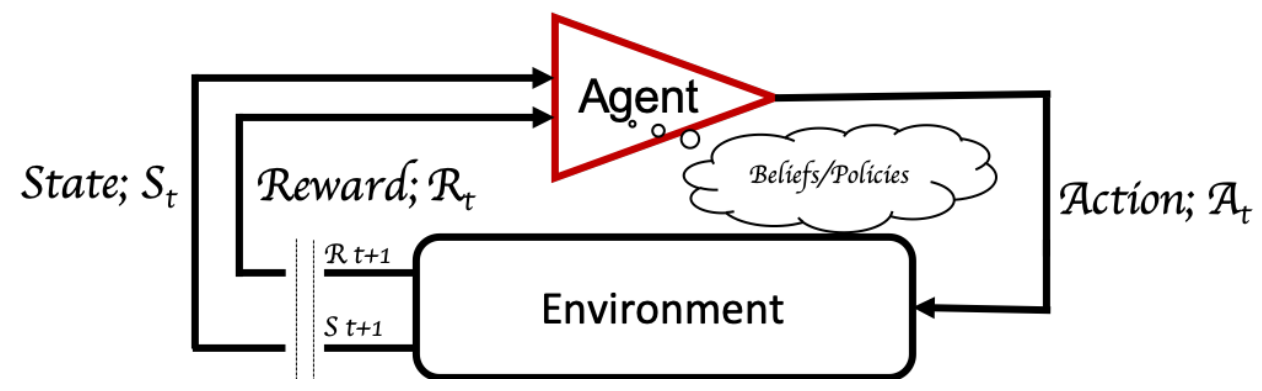

Figure 1: Schematic overview of the reinforcement learning framework (Adapted from Sutton \& Barto, 2018).

Evidence suggests that learning to interact with novel environments can be characterized by some form of Bayesian learning (Daw et al., 2005, 2006; Dayan \& Daw, 2008; Knill \& Pouget, 2004; Marković \& Kiebel, 2016; Mathys et al., 2011; Nassar et al., 2010). In Bayesian learning, in contrast to classic reinforcement learning, learning occurs faster when the learner experiences more uncertainty. Because of this feature it was argued that Bayesian models resemble how individuals assimilate new information into their beliefs across development (Frankenhuis \& Panchanathan, 2011; Gopnik et al., 2017; Stamps \& Frankenhuis, 2016; Tenenbaum et al., 2011)

From this point of view, many developmental tasks are about navigating a complex and uncertain environment in order to find a good solution based on experience. Such a task presents the learner with an explore-exploit dilemma (Addicott et al., 2017; Gopnik, 2020). Too much exploitation (choosing known good options) prevents the learner from gathering new information, and thus one may miss out on even more rewarding options. Too much exploration (gathering novel information), may be inefficient because of the high opportunity cost associated with not sampling the best option, thereby reducing long-term prospects.

The most widely used paradigm to study this dilemma is the multi-armed bandit task (Daw et al., 2006). It mirrors a casino's slot-machine with multiple arms, where each arm is associated with a different reward distribution. Obtaining a reliable understanding of all possible rewards will require vast amounts of exploration; requiring time or resources that could be spent pulling the most optimal arm, hence the dilemma. How much exploration is rational not only depends on individual experience but also on the environment which learners find themselves in. For instance, in a novel or volatile environment, more exploration is beneficial, while in a stable and well-known world, exploitation becomes more attractive (Behrens et al., 2007; Mathys et al., 2011). When there is considerable 
uncertainty, social information can reduce the need for exploration by providing information about what should be exploited or avoided by simply observing others (Mehlhorn et al., 2015).

Studying learning of artificial agents provides a laboratory for understanding the dynamics in human learning as well (Gershman et al., 2015; Rahwan et al., 2019). Since reinforcement learning formalizes the interaction between agent and environment, we however need to zoom in on some specific aspects of the adolescent environment in order to generate a meaningful metaphor for adolescent development. First, parental oversight is decreasing when adolescence begins, and the opportunities for engaging in risky behaviour increase (Sercombe, 2014; Willoughby et al., 2013). Second, these opportunities have often not been explored before, making their benefits uncertain and because losses are possible, exploring those opportunities carries a risk (Hertwig et al., 2019). Third, there are significant changes in the social world (Blakemore \& Mills, 2014).

In the following, we focus on these three salient features of the adolescent environment: 1) increasing opportunity for risks, 2) uncertainty about the world and 3) the presence of peers, and implement Bayesian learning agents who explore this environment. These agents possess a simple set of rules according to which they act, but viewing their behaviour simultaneously and over time will unravel complex properties, beyond the simple decision rules of one individual at one point in time (Bonabeau, 2002). By these means, we show how exploration and learning, together with changes in the environment, can lead to outcomes that resemble developmental trajectories of risk-taking and social susceptibility observed in adolescents, without assuming developmental changes in reward or social sensitivity.

\section{Methods}

\section{The simulated environment}

We simulate an environment, carrying three features of the environment adolescents face to show that adolescent-specific risky-behaviour may emerge merely from learning and exploration. First, it increases in the number of options after an initial childhood learning period. Second, exploration is risky and could lead to gains but also losses. We assume that adolescents have access to more dangerous options (with more negative outcomes) than those provided in childhood. Third, there is social information, meaning that similar agents explore the same environment simultaneously, and agents can observe each other. 


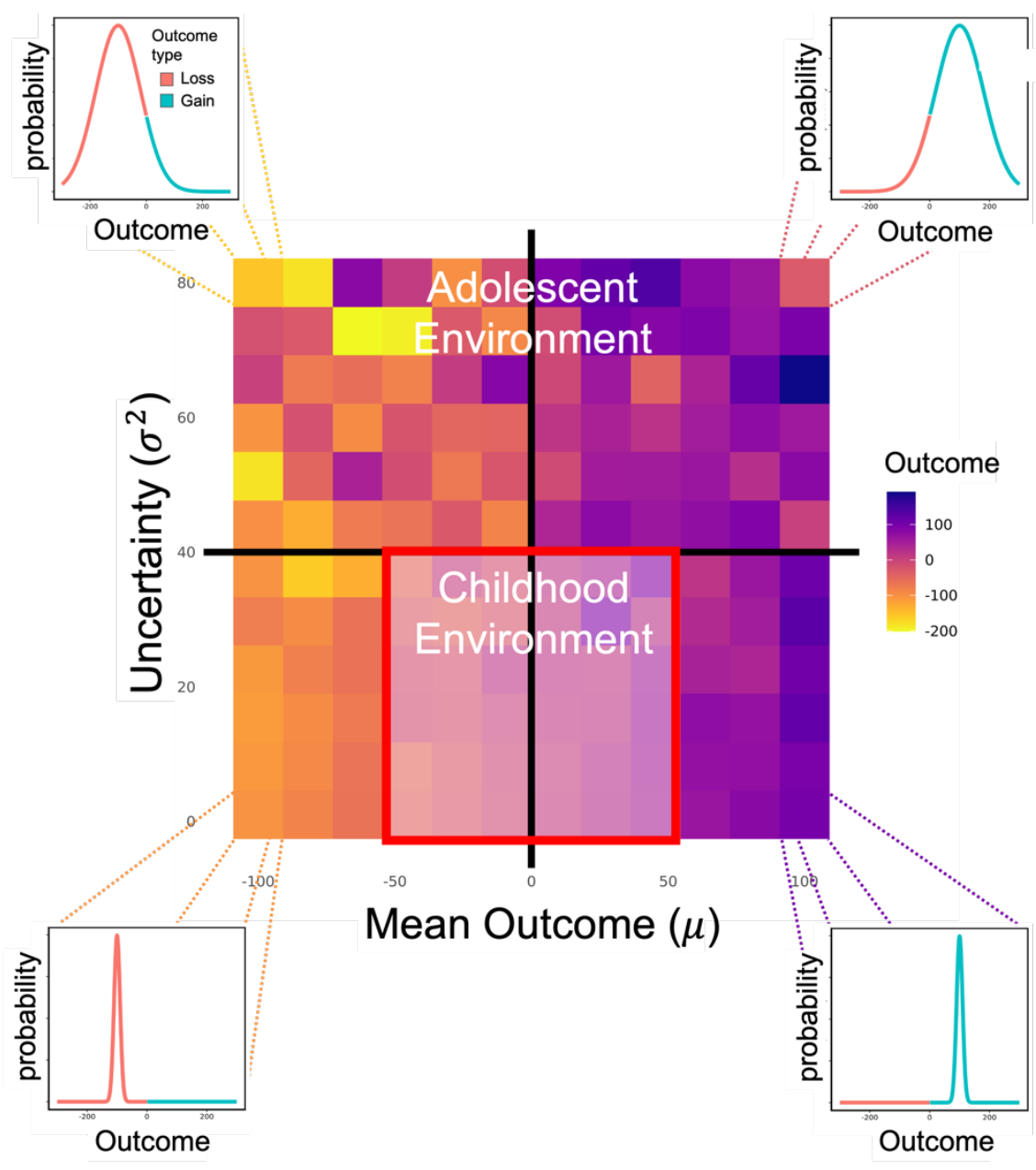

Figure 2: The 144-armed bandit used for our simulations. Each square represents one possible outcome from its underlying reward distribution. Examples for the most extreme distributions in our environment are depicted in the margins, where the $y$ axis shows the probability to receive the outcome on the $x$-axis. The environment offers different amounts of expected rewards ( $x$-axis) to varying degrees of uncertainty ( $y$-axis). The middle grid within the red square depicts a "child" agent's search space, constricted to medium-sized gains and losses with relatively low risk. The whole grid shows an "adolescent" and "adult" agent's search space, where large gains and losses are possible at high and low levels of risk.

The simulated environment confronts our learning agents with a multi-armed bandit problem, which is often used to study how humans trade-off exploration with exploitation (Daw et al., 2006; Schulz et al., 2019; Wu et al., 2018). The problem consists of 144 different options, each associated with another reward distribution ( ), which agents can explore to find an option that maximizes long term rewards. Every time the agent decides for one option, the environment produces an outcome: a random draw from a normal distribution. The outcome is either positive (gain) or negative (loss). Options differ in their expected reward (from -100 to 100) and variance (from 5 to 80 ). By varying mean and variance of the options' underlying distribution, we generated an environment in which exploration is risky (Sani et al., 2012), according to the definition of risk-taking: sampling a novel option can result in losses, and there is uncertainty about the outcomes (Hertwig et al., 2019). The environments' complexity increases in two stages. In the first stage, agents can only explore a constrained section of their environment, with 36 options to sample. These options are relatively predictable (the variance 
ranges from 5 to 40 ) and avoid great losses and rewards (the mean ranges from -50 to 50). This reflects a childhood period where adults strongly restrict the environment of children to keep them safe. In the second stage, we introduce novel options to explore. These options are both better and worse than those presented in the childhood world, echoing the risks and opportunities of adolescence (Dahl, 2004).

\section{Agents}

We can break down the agents' into three elements: beliefs, a belief update rule and a choice rule. When making a decision, our agents can either take a risk and switch away from the best option they know so far, or they can exploit their knowledge base and stay with this option. In our implementation (Daw et al., 2006; Schulz et al., 2019), agents learn and update their beliefs about their environment's statistical structure using Bayes rule (figure 3).

A

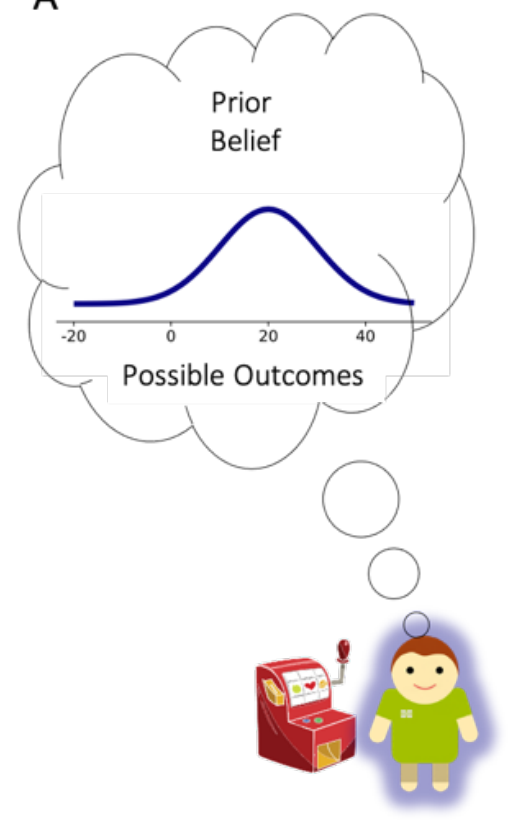

B

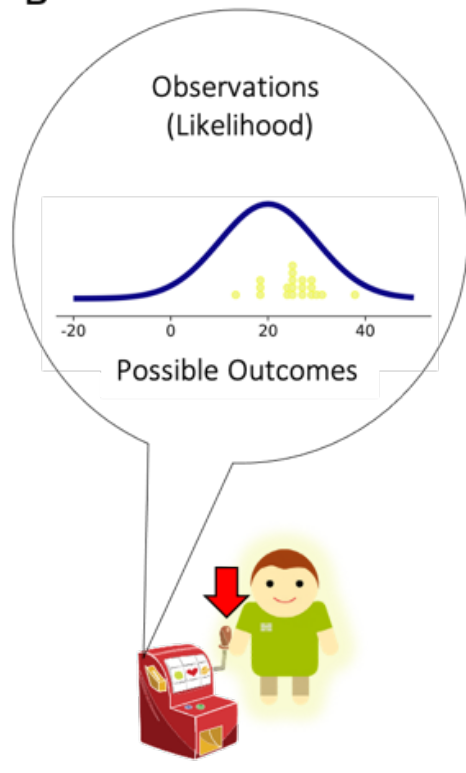

C

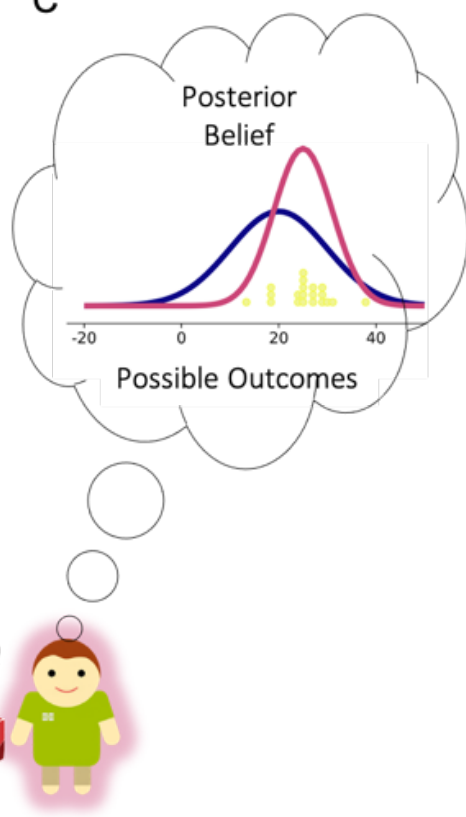

Figure 3: Belief update for the example of one option in the environment. A) An agent ${ }^{1}$ approaches each option in the environment with a prior belief about how rewarding this option could be, but is uncertain about it, as can be seen in the spread of the prior distribution. B) Exploring this option will produce outcomes which the agent experiences. C) Experiencing outcomes will help the agent adapt its belief to the environment, as the mean of the agent's beliefs shifts towards the observations and the agent is more certain as the posterior's spread is smaller than the spread of the prior.

At every point in time, $t$, believe each option $j$ in their environment, to results in some reward $(\mu)$, but are uncertain $\left(\sigma^{2}\right)$, about their expectations (figure 3A). They update their beliefs after every decision with a prediction error. The prediction error is the difference between the reward expected

\footnotetext{
${ }^{1}$ The avatar image by LeonardolannelliCOMPUTE is licensed under CC BY 4.0.
} 
by the agent $\left(\mu_{\mathrm{j}, \mathrm{t}-1}\right.$; figure $\left.3 \mathrm{~A}\right)$ and the actual reward received after deciding for an option $\left(\mathrm{y}_{\mathrm{j}, \mathrm{t}}\right.$; figure 3B). For a given option, the mean and uncertainty are updated when the option was selected (figure 3C):

$$
\begin{gathered}
\mu_{\mathrm{j}, \mathrm{t}}=\mu_{\mathrm{j}, \mathrm{t}-1}+\zeta_{\mathrm{j}, \mathrm{t}} \mathrm{K}_{\mathrm{j}, \mathrm{t}}\left(\mathrm{y}_{\mathrm{j}, \mathrm{t}}-\mu_{\mathrm{j}, \mathrm{t}-1}\right), \\
\sigma_{\mathrm{j}, \mathrm{t}}^{2}=\sigma_{\mathrm{j}, \mathrm{t}-1}^{2} *\left(1-\zeta_{\mathrm{j}, \mathrm{t}} * \mathrm{~K}_{\mathrm{j}, \mathrm{t}}\right),
\end{gathered}
$$

Where $\zeta_{\mathrm{j}, \mathrm{t}}=1$ if option $j$ is chosen on trial $t$, and 0 otherwise. $K$ refers to the Kalman gain, which can be interpreted as a learning rate and is defined by the agents' uncertainty:

$$
\mathrm{K}_{\mathrm{j}, \mathrm{t}}=\frac{\sigma_{\mathrm{j}, \mathrm{t}-1}^{2}}{\sigma_{\mathrm{j}, \mathrm{t}-1}^{2}+\epsilon_{j}} .
$$

$\epsilon$ is an error constant, denoting the range of outcomes expected in the whole environment. Notably, in an analogy to Bayesian models of human development (Frankenhuis \& Panchanathan, 2011; Tenenbaum et al., 2011), when agents are more experienced they will change their beliefs about their environment less. We set the initial beliefs about unchosen options to be optimistic, but very uncertain $\left(\mu_{0}=100, \sigma_{0}^{2}=40\right)$. We choose relatively optimistic priors (the mean expected reward prior was 100, whereas the actual mean reward rate of the whole environment is 0 ), for two reasons: First, this motivates agents to leave the safe "childhood" space, given that the agents expect to find higher rewards outside of it. Second, a single negative outcome will not directly lead to a very negative belief about an option, thus inviting further exploration.

\section{Social learning}

To understand how social information shapes risky exploration, multiple agents could observe each other while solving the explore-exploit trade-off simultaneously. Each agent expects an option to be more rewarding when other agents also explore it:

$$
\mathrm{U}_{\mathrm{j}, \mathrm{t}}=\mu_{\mathrm{j}, \mathrm{t}}+\mathrm{N}_{\mathrm{j}, \mathrm{t}-1}^{\alpha},
$$

$\mathrm{N}$ is the total number of other agents exploring an option and $\alpha$ maps social mass $\mathrm{N}$ to social impact. In our simulations, we set this parameter to 0.8 , which means that social impact increases strongly when a few individuals explore this option. When social mass gets bigger, one additional individual's impact becomes small (Latané, 1981). The "social bonus" is added to the observing agent's utility function $(U)$ in the next round. Finally, all options' $U_{t}$ are fed into a softmax function to obtain the probability that an agent will choose the respective option, $\mathrm{j}$

$$
p(j)=\frac{\exp \left(U_{j, t}\right)}{\sum_{i=1}^{n} \exp \left(U_{i, t}\right)} .
$$


We do not model developmental changes in any of the model parameters. Thus, the model is in contrast with theories suggesting that adolescents are more sensitive to social information or rewards than children and adults. It was our goal to show how typical adolescent behaviour may emerge simply by the interaction of experience and environmental changes.

\section{Simulations}

Each agent made 1200 sequential decisions, the first 400 of which in the "childhood environment", the other 800 in the "adolescent environment" (figure 2) after new options have been made available to the agents. We performed two sets of simulations. In a solo condition, agents explored the environment alone. In a social condition, 20 agents explore the environment simultaneously and influence each other according to equation 4.

\section{Behavioural measures}

To assess the change in risky behaviour across "development" we calculated the average number of explorative decisions made by our agents in bins of 50 consecutive choices. In the multi-armed bandit problem, exploration can mean switching from one arm to another (Daw et al., 2006). Exploring is associated with risk because some options in the environment carry the danger of losses, and there is uncertainty about when and if these options will lead to bad outcomes (Hertwig et al., 2019). To understand the consequences of exploration, we examine how many losses and gains the agents encountered and their average magnitude. Finally, we quantified social learning by calculating how often an agent samples options that other agents sampled previously, in other words how often the agent followed others (again, the average per 50 trials). In our simulations, there is no explicit third transition into an "adult environment" (see Discussion), however, for illustration purposes, we analysed the behaviour of our agents within three equally sized bins (childhood, adolescence and adulthood), each corresponding to 400 choices made by the agents.

\section{Results}

\section{Exploration and social following}

Here we investigate how explorative behaviour changes as a function of experience and the environment in agents who did and did not access social information. As shown in figure 4A, both childhood and adolescence are generally characterized by exploratory behaviour that declines with age. Within our simulations, this can be attributed to the many new options that became available simultaneously. Such an adolescent peak and decline in exploration simply emerges from increased 
opportunities and subsequent learning in the absence of specific adolescent sensation-seeking or reward sensitivity. When agents had the opportunity for social learning, exploration was reduced as compared to solo behaviour during adolescence. We also see that there is substantial social following behaviour in childhood and another peak in early adolescence (figure 4 B). As agents gain more experience, following others declines.
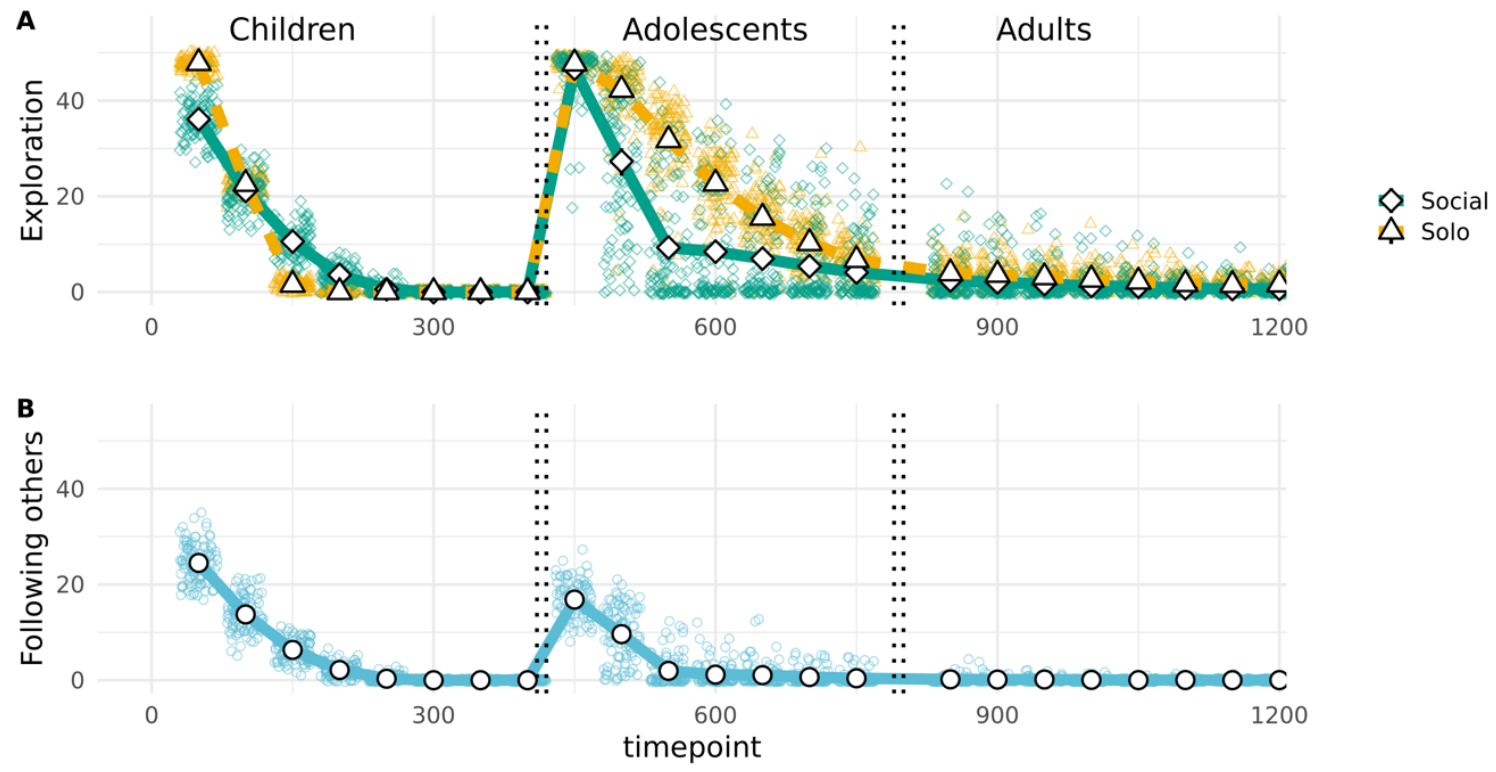

Figure 4: A) Exploration ( $y$ axis) by timepoints in the simulations ( $x$-axis) and whether agents hat access to social information (green) or not (yellow). Each shape denotes the average number of switches over the past 50 decisions per developmental stage and depending on whether agents had access to social information. Small transparent shapes denote individual simulations, and large shapes cover the mean and $95 \%$ ci of the mean of all simulations. Explorative decisions are defined as the decision to switch from one to another option. While both, childhood and adolescence can be characterized by relatively high exploration, the adolescent environment leads agents to explore their environment for a prolonged time. B) Decisions to explore an option that others had sampled before ( $y$-axis), when the agent explored independently before. Both, exploration and social following increase in "adolescence" when there are novel options to explore.

\section{Experienced outcomes}

Here we show the number of positive and negative outcomes encountered by exploring agents in different "developmental stages" and show how severe those outcomes were. Overall, the number of experienced losses declines, the number of experienced rewards increases.

In both metrics, number of losses or gains and their magnitude, social information was beneficial, resulting in more gains and less losses as well as better outcomes for gains and losses (figures 5A and 5C). We further observe that adolescent agents experience the most severe losses (figure 5B) irrespective of whether social information was available or not, however on average using social information seemed beneficial for adolescent agents in the loss (figure 5C) and in the gain domain (figure 5D). 


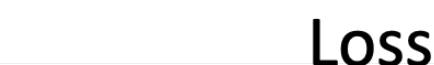

A

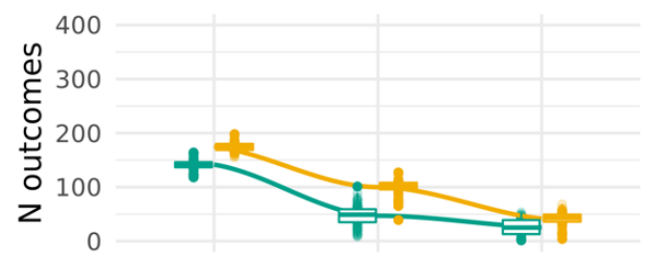

B

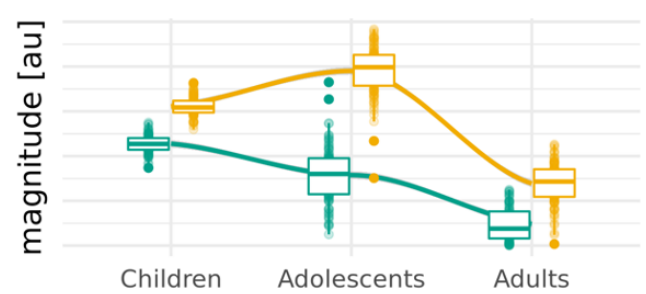

C

\section{Gain}

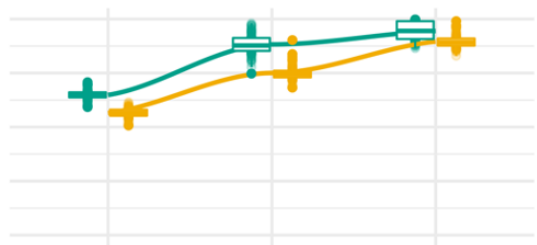

D

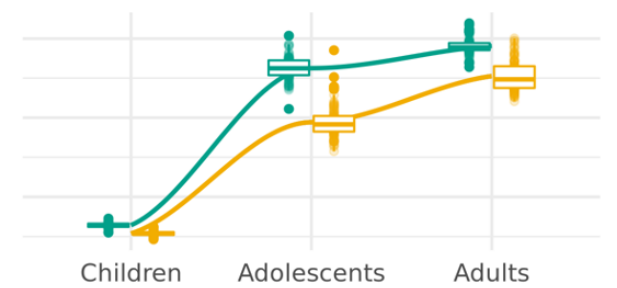

Social

Solo

Figure 5: Outcomes experienced for non-social (yellow) and social (green) agents. Outcomes that are either negative (Loss) or positive (Gain) by age group for each of the $\mathbf{1 0 0}$ simulations (dots). The first row depicts the cumulative count of A) losses and C) gains. The second row shows the magnitude of a given outcome for $B$ ) losses and D) gains. As agents progress through the developmental stages, they encounter fewer losses and more gains. Notably, during adolescence, the social following rule induces a greater variance in positive and negative outcomes compared to simulations that did not include social information.

\section{Discussion}

In his book "The Sciences of the Artificial", Nobel laureate Herbert Simon contemplates the trajectory of an ant wandering on the beach. Looking from above, the ant's path is "irregular, complex, and hard to describe". An apt description for many adolescents' choices. But, as Simon points out, the complexity is in the surface of the beach, not in the ant; "An ant, viewed as a behaving system, is quite simple. The apparent complexity of its behaviour over time is largely a reflection of the complexity of the environment in which it finds itself", (Simon, 2019, p.52). Here we argue that we also have to pay attention to interaction between the adolescent and their complex environment. We stress that 1 ) adolescents are required to learn to interact with the novel adult environment (Sercombe, 2014; Willoughby et al., 2013), and 2) exploring this environment is inherently risky since it is often uncertain whether the behaviour will be harmful or not (Hertwig et al., 2019; Sani et al., 2012) and 3) the environment is filled with opportunities for social learning (Crone \& Dahl, 2012; Nelson et al., 2016). We illustrate how agent-based simulations help to further our intuitions about the interactions between adolescents and their environment.

One of the striking results is that our simulations reproduce a set of very typical adolescent behaviours; 1) an inverted U shape in risky exploratory behaviour (Romer et al., 2017; Steinberg et al., 
2018), and 2) increased peer-following in early but not late adolescence (Braams et al., 2019; Rodriguez Buritica et al., 2019). The increased exploration was associated with selecting risky high variance options, which resulted in a peak of severe losses during adolescence. However, this risky exploration was beneficial because it helped the agents maximize rewards in the long run. Additionally, social information helped them to avoid some severe losses and learn about good options faster. Importantly, these patterns emerged even without needing to invoke specific "motivational" changes in the adolescent agents. That is, the agents exploration bonus for novel options was the same across all stages, as was the utility attributed to options chosen by others. Instead, the changes in behaviour emerged from changes in the environment (e.g. opening up in adolescence) and experience (rewards and losses). These stylized facts generated in an oversimplified world provide valuable insights into how adolescent-specific risk behaviour may emerge, emphasizing a central role for learning and experience. In the following, we discuss how our perspective relates to findings and theoretical frameworks on adolescent risky and social behaviour and their neural development, suggesting novel avenues for future research.

\section{Adolescent biology}

Although the agents in our simulations do not go through any developmental changes, it is indisputable that there are major biological changes during adolescence in humans and animals (Luna et al., 2013; Mills et al., 2014; Worthman \& Trang, 2018). First and foremost, the start of adolescence is defined by the start of puberty, which is marked by a significant rise in pubertal hormones. Second, neuroimaging studies revealed considerable changes in brain structure and function during the second decade of life. According to dual systems models of neural development (Luna et al., 2013; Nelson et al., 2016; Shulman et al., 2016), risk-taking peaks during adolescence because of a maturational imbalance between an early-maturing dopaminergic reward processing system and a still immature cognitive control system that is not (yet) strong enough to restrain reward-seeking impulses. Given the co-occurrence of puberty and maturational imbalance, it was suggested that hormonal changes related to puberty drive developmental changes in risk-taking (Braams et al., 2015).

We do not argue against the empirical findings that form the basis for these theories, however, we argue for a broader perspective, stressing that the interaction with the environment leads to experience, and experience itself leads to changes in brain and behaviour (Romer et al., 2017; Sercombe, 2014). For instance, dopamine and pubertal hormones are also known to enhance learning. A body of work shows that pubertal hormones play a pivotal role in regulating the mechanisms of experience-dependent neuronal plasticity during adolescence (for review, see Laube et al., 2020). In addition, changes in dopamine function during adolescence may play a key role in experience-based 
fine-tuning of neural systems (Murty et al., 2016). Early on it was pointed out that developmental changes in grey matter most likely reflect experience-based pruning of cortical networks (Giedd et al., 1999), but environmental changes can also cause changes in the mesolimbic dopamine system. For instance, the mesolimbic dopamine system's in vivo activity is enhanced by moving rats to an enriched environment (Segovia et al., 2010). A recent study showed that both striatal dopamine release and dopamine synthesis capacity are significantly elevated in immigrants compared to non-immigrants (Egerton et al., 2017). Thus, it is conceivable that the enhanced level of striatal dopamine, or other neural changes, associated with adolescence is also a response to being confronted with a novel and stressful social environment, rather than just a biological timer going off. In sum, a broader perspective on adolescent risk may also bring some nuance to the interpretation of current neuroimaging findings.

\section{Understanding risk}

We argue that to understand adolescent risk-taking, there is a need to conceive risk-taking not only as impulsive or flawed behaviour but also as an exploratory activity that resolves uncertainty and is necessary to achieve developmental milestones, generates wisdom and knowledge (Rivers et al., 2008) and is often planned (Romer et al., 2017). Refocusing on experience and learning has consequences for studying risk-taking in the laboratory. That is, instead of static forced-choice decision experiment, paradigms involving uncertainty or necessitating exploration might prove more valuable for understanding laboratory correlates of real-life risk taking (Frey et al., 2017; Rosenbaum et al., 2018). Indeed, experimental research studying risk-taking under uncertainty (Blankenstein et al., 2016; Braams et al., 2015; van den Bos \& Hertwig, 2017), or exploration (Somerville et al., 2017) elicit behaviour that is predictive of real-life risk taking. The advantage of experimental studies is that they diminish the role of developmental differences in prior experience or knowledge by exposing everybody to a novel environment.

Throughout this manuscript, we used Bayesian reinforcement learning to quantify intuitions arising from focusing on exploration across development (Frankenhuis \& Barto, 2019), but the simulated environment also allows for a concrete implementation as experiment (Schulz et al., 2019; Wu et al., 2018). If children, adolescents and adults would be confronted with our environment in an experiment, this experiment would be sensitive to developmental differences in exploration not induced by their ecology but by differences in internal drives. Indeed, evidence from self-report and experimental studies shows that novelty and sensation seeking is at its peak during adolescence (Crone et al., 2008; Maslowsky et al., 2019; Wills et al., 1994). An increase in novelty seeking translates to more optimism in our agents and would lead to increased exploration. Sensation seeking, other 
than novelty seeking, involves a preference for activities that have high variance in expected value (Zuckerman et al., 1978). Translating this to our simulations and models, a sensation seeking agent would seek out uncertainty and prefer options in the top quadrants of Figure 2, containing highvariance options. Individuals with a propensity for sensation seeking will be driven to explore more, given that all unknown options are associated with high variance, and finally converge somewhere on the top right, generally experiencing positive outcomes, but also some infrequent very negative ones. If sensation seeking would decline with age, the agents would move to options with lower variance. Although, we here illustrated that an adolescent specific increase in novelty (Cloninger, 1986) or sensation seeking (Romer et al., 2017) is not a necessary prerequisite to explain an adolescent rise and fall in risky behaviour when considering their ecology, we believe a complete model incorporates these additional factors.

\section{Peer influence and social learning}

In our simulations, there was peak of social information use at the beginning of "adolescence" when novel opportunities raised for our agents, suggesting social sensitivity is related to exploration and uncertainty. In the real world, adolescence is a period of major social upheaval. During this period, adolescents become preoccupied with how their peers view them (Somerville et al., 2013) and how they fit into their social groups (Coleman et al., 1977). One might argue that the social context becomes an adolescent's main source of uncertainty. Learning how this social world works, who they are, and where they fit in, are major developmental tasks for adolescents (Nelson et al., 2016). The mere presence of peers, is arousing to adolescents, which may shift the neural balance between reward and control such that it leads to an increase in (impulsive) risk-taking (Chein et al., 2011; Gardner \& Steinberg, 2005c; Shulman et al., 2016). Others have emphasized that some risk-taking behaviour might aim at reaching social goals, such as status and belonging (Blakemore \& Mills, 2014; Telzer et al., 2018). Here, we highlight another aspect: following or copying others' behaviour, can be a smart form of social learning (Bandura, 1962). Research in adult social learning has shown that social information use often follows a basic principle which is that people use more social information when they are more uncertain or feel less confident (Ciranka \& van den Bos, 2020; De Martino et al., 2017; Molleman et al., 2014; Moutoussis et al., 2016; Toelch \& Dolan, 2015; Tump et al., 2020). In a novel environment, using social information is beneficial because it informs individuals about good options without the potential dangers of trial and error learning ${ }^{2}$ (Hoppitt \& Laland, 2013; Mehlhorn et al.,

\footnotetext{
${ }^{2}$ Social information is not always good and conformity can also lead to bad outcomes. We also find in our simulations that if there is too much conformity, this can lead to suboptimal outcomes.
} 
2015; Todd \& Brighton, 2016). In line with that, we show that agents who transition into the adolescent environment, in which they are maximally uncertain, use social information most. In addition, we show that combining their knowledge, social agents converge quicker on better options compared to searching for these alone. There are still some severe losses, and sometimes the agents followed a bad example, but overall "adolescent agents" benefited from following their peers. Since social learning allows individuals to avoid experiencing bad outcomes, conformity may be particularly strong for avoidance learning. Several studies have shown that adolescents may also be specifically sensitive to social information promoting risk-avoiding behaviour (Braams et al., 2019; Chung et al., 2020; Ciranka \& van den Bos, 2019; Engelmann et al., 2012), which could reflect an adaptation to their uncertain ecology.

The social learning perspective also raises questions. If adolescent risk-taking can also be characterized by social learning and depends on uncertainty, identifying adolescents' uncertainties will help to understand where they are most likely to give in to peer pressure for two reasons. First, situations in which adolescents are uncertain about whether some behaviour is "worth the risk" will be those situations where they are most susceptible to peer influence. Second, uncertainty about others can influence adolescent risk-taking when social learning is not possible. This is because uncertainty itself is related to acute stress responses and arousal in humans when they anticipate negative outcomes (de Berker et al., 2016) or take risks (FeldmanHall et al., 2016). When adolescents find themselves observed by others, they more often anticipate negative outcomes, like being rejected or embarrassed than children or adults (Crone \& Konijn, 2018; Pickett et al., 2004; Rodman et al., 2017; Somerville et al., 2013). Thus, their uncertainty about others' mental states in combination with their bias towards predicting negative social outcomes may contribute to adolescents' arousal which is, in turn, thought to nudge them into reward-sensitivity and risk-taking in social contexts (Shulman et al., 2016).

\section{Limitations and extensions}

Exploratory behaviour in our simulations not only reduces because the agents are learning but also because there is a finite set of options. In the real world, adults take on multiple roles that provide different opportunities and risks (Willoughby et al., 2013). However, we focused on a fixed set of choices given that this mimics what adolescent risk-taking is concerned with. For instance, the selected items on adolescent risk-taking questionnaires, mainly include options that become more easily available during adolescence such as activities related to substance abuse, driving, and sex (Gullone et al., 2000). It is an empirical question whether options that become available to adults have the same potential for harm on the individual level, but clearly novel opportunities will arise. 
Simulations could integrate an ever-increasing set of options, by adding them later, resulting in another increase in exploratory behaviour, given that our agents' priors were the same for every new option. Thus, our model does not predict that adults would not take risks or explore anymore, but assumes risk-taking to be determined by the interaction with agents and their environment. By these means, the model can explain why risk-taking in certain areas significantly reduces across adolescence, presumably based on experience, while other risks for instance white collar crimes, which may be much more harmful to society than the risks adolescents take, have a much later peak (Benson \& Kent, 2001). Furthermore, our model predicts that significant changes in adults' ecology stage will result in a new spike in exploration and social following behaviour. Although it is the common trope that adolescents will jump off the bridge if all their friends would do it, there is plenty of evidence of adults showing the same herding behaviour when there is uncertainty, for instance in real estate markets (Babalos et al., 2015) or cryptocurrencies (Coskun et al., 2020). More recently, following the Covid-19 outbreak, we have seen herding in hoarding of toilet paper in several countries around the world (Garbe et al., 2020; Kirk \& Rifkin, 2020). Thus, when there is novelty and uncertainty, explorative or risky behaviour and social susceptibility will re-occur in adulthood. Exploring this in further studies based on sound intuitions about what type of affordances the adult environment provides will be most insightful.

Further, although agents can suffer losses in simulations, they could never get hurt or even die. Introducing this possibility would generate evolutionary dynamics, such as loss aversion, and would call for a using social information strategically, something adolescents are known to do (Chung et al., 2015; Ciranka \& van den Bos, 2019). Generally, studies from across the biological and social sciences suggest that people use social information strategically; they are selective as to who they turn to for useful knowledge (Hoppitt \& Laland, 2013). Developmental studies have shown that adolescents are more likely to rely on expert advice than adults when taking financial risks (Engelmann et al., 2012). On the other hand, peers might be a more important information source to adolescents when it comes to risk-perception (Knoll et al., 2015). It would be of great interest to study how decisions about when and whom to learn from, operate across adolescence specifically because the literature suggests that adolescents are exceptionally sensitive to social status (Yeager et al., 2018). Finally, the model assumes that all individuals initially have equal opportunities to benefit from the environment. In reality, parents' socioeconomic status influences the risks and opportunities that children are exposed to (Frankenhuis et al., 2016; Worthman \& Trang, 2018). It will be insightful to quantify how such inequalities impact risky behaviour during the adaptive mind's development. 


\section{Summary and Conclusion}

The ecological approach has a long tradition in developmental (Bronfenbrenner, 1979) and decision science (Simon, 1956). It proposes that cognitive and motivational systems are shaped-by evolution or development-to take advantage of the external environment's structure (Gigerenzer \& Gaissmaier, 2011; Todd \& Brighton, 2016). Thus, to understand behaviour, it is necessary to understand the environment it occurs in. Here, we highlighted the role of learning and experience in this process. In the past decades, much research has focused on the adolescent mind's inner workings to understand the mechanisms behind adolescent risk-taking. Our agent-based models illustrate that exploration and adaptation to an uncertain environment itself can give rise to typical adolescent patterns in risk behaviour and peer influence without assuming developmental changes in internal drives. Although the claim that risk-taking may be adaptive is not new, we point out that models of adolescent risk-taking and peer influence, must integrate elements of learning, experience and the environment that adolescents adapt to. Such models would paint a fairer picture of adolescents, not just as individuals with unfinished brains and raging hormones, but as active learning agents who are exploring a new and uncertain world.

\section{References}

Addicott, M. A., Pearson, J. M., Sweitzer, M. M., Barack, D. L., \& Platt, M. L. (2017). A Primer on Foraging and the Explore/Exploit Trade-Off for Psychiatry Research. In Neuropsychopharmacology (Vol. 42, Issue 10, pp. 1931-1939). Nature Publishing Group. https://doi.org/10.1038/npp.2017.108

Albert, D., Chein, J., \& Steinberg, L. (2013). The Teenage Brain: Peer Influences on Adolescent Decision Making. Current Directions in Psychological Science, 22(2), 114-120. https://doi.org/10.1177/0963721412471347

Babalos, V., Balcilar, M., \& Gupta, R. (2015). Herding behavior in real estate markets: Novel evidence from a Markov-switching model. Journal of Behavioral and Experimental Finance, 8, 40-43. https://doi.org/10.1016/j.jbef.2015.10.004

Bandura, A. (1962). Social learning through imitation. In M. R. Jones (Ed.), Nebraska Symposium on Motivation (pp. 211-274). Univer. Nebraska Press.

Behrens, T. E. J., Hunt, L. T., Woolrich, M. W., \& Rushworth, M. F. S. (2008). Associative learning of social value. Nature, 456(7219), 245-249. https://doi.org/10.1038/nature07538

Behrens, T. E. J., Woolrich, M. W., Walton, M. E., \& Rushworth, M. F. S. (2007). Learning the value of 
information in an uncertain world. Nature Neuroscience, 10(9), 1214-1221.

https://doi.org/10.1038/nn1954

Benson, M. L., \& Kent, R. K. (2001). Life Course Theory and White Collar Crime. In H. N. Pontell \& D. Shichor (Eds.), Contemporary Issues in Crime and Criminal Justice: Essays in Honor of Gil Geis (pp. 121-136).

Biele, G., Rieskamp, J., Krugel, L. K., \& Heekeren, H. R. (2011). The Neural Basis of Following Advice. PLoS Biology, 9(6), e1001089. https://doi.org/10.1371/journal.pbio.1001089

Blakemore, S.-J., \& Mills, K. L. (2014). Is Adolescence a Sensitive Period for Sociocultural Processing? Annual Review of Psychology, 65(1), 187-207. https://doi.org/10.1146/annurev-psych-010213115202

Blankenstein, N. E., Crone, E. A., van den Bos, W., \& van Duijvenvoorde, A. C. K. (2016). Dealing With Uncertainty: Testing Risk- and Ambiguity-Attitude Across Adolescence. Developmental Neuropsychology. https://doi.org/10.1080/87565641.2016.1158265

Bonabeau, E. (2002). Agent-based modeling: Methods and techniques for simulating human systems. Proceedings of the National Academy of Sciences of the United States of America, 99(SUPPL. 3), 7280-7287. https://doi.org/10.1073/pnas.082080899

Bowers, K., \& Natterson-Horowitz, B. (2020). Wildhood: the astounding connections between human and animal adolescents. Scribner.

Braams, B. R., van Duijvenvoorde, A. C. K., Peper, J. S., \& Crone, E. A. (2015). Longitudinal Changes in Adolescent Risk-Taking: A Comprehensive Study of Neural Responses to Rewards, Pubertal Development, and Risk-Taking Behavior. Journal of Neuroscience, 35(18), 7226-7238. https://doi.org/10.1523/JNEUROSCI.4764-14.2015

Braams, Barbara R., Davidow, J. Y., \& Somerville, L. H. (2019). Developmental patterns of change in the influence of safe and risky peer choices on risky decision-making. Developmental Science, 22(1), e12717. https://doi.org/10.1111/desc.12717

Bronfenbrenner, U. (1979). The Ecology of Human Development.

Chase, V. M., Hertwig, R., \& Gigerenzer, G. (1998). Visions of rationality. Trends in Cognitive Sciences, 2(6), 206-214. https://doi.org/10.1016/S1364-6613(98)01179-6

Chein, J. M., Albert, D., O’Brien, L., Uckert, K., \& Steinberg, L. (2011). Peers increase adolescent risk taking by enhancing activity in the brain's reward circuitry. Developmental Science. https://doi.org/10.1111/j.1467-7687.2010.01035.x

Chung, D., Christopoulos, G. I., King-Casas, B., Ball, S. B., \& Chiu, P. H. (2015). Social signals of safety 
and risk confer utility and have asymmetric effects on observers' choices. Nature Neuroscience, 18(6), 912-916. https://doi.org/10.1038/nn.4022

Chung, D., Orloff, M. A., Lauharatanahirun, N., Chiu, P. H., \& King-Casas, B. (2020). Valuation of peers' safe choices is associated with substance-naïveté in adolescents. Proceedings of the National Academy of Sciences, 7, 201919111. https://doi.org/10.1073/pnas.1919111117

Cialdini, R. B., \& Goldstein, N. J. (2004). Social Influence: Compliance and Conformity. Annual Review of Psychology, 55(1), 591-621. https://doi.org/10.1146/annurev.psych.55.090902.142015

Ciranka, S., \& Bos, W. van den. (2020). A Bayesian Model of Social Influence under Risk and Uncertainty. Proceedings of the 42ndth Annual Conference of the Cognitive Science Society. https://doi.org/10.31234/OSF.IO/MUJEK

Ciranka, S., \& van den Bos, W. (in press). Social norms in adolescent risk engagement and recommendation. British Journal of Developmental Psychology. https://doi.org/10.1111/bjdp.12369

Ciranka, S., \& van den Bos, W. (2019). Social influence in adolescent decision-making: A formal framework. Frontiers in Psychology, 10(AUG), 1915. https://doi.org/10.3389/fpsyg.2019.01915

Cloninger, C. R. (1986). A unified biosocial theory of personality and its role in the development of anxiety states. Psychiatric Developments, 4(3), 167-226. https://europepmc.org/article/med/3809156

Coleman, J., Herzberg, J., \& Morris, M. (1977). Identity in adolescence: Present and future selfconcepts. Journal of Youth and Adolescence, 6(1), 63-75. https://doi.org/10.1007/BF02138924

Collins, A. G. E., \& Cockburn, J. (2020). Beyond dichotomies in reinforcement learning. Nature Reviews Neuroscience, 1-11. https://doi.org/10.1038/s41583-020-0355-6

Coskun, E. A., Lau, C. K. M., \& Kahyaoglu, H. (2020). Uncertainty and herding behavior: evidence from cryptocurrencies. Research in International Business and Finance, 54, 101284. https://doi.org/10.1016/j.ribaf.2020.101284

Crone, E. A., Bullens, L., van der Plas, E. A. A., Kijkuit, E. J., \& Zelazo, P. D. (2008). Developmental changes and individual differences in risk and perspective taking in adolescence. Development and Psychopathology, 20(04), 1213. https://doi.org/10.1017/S0954579408000588

Crone, E. A., \& Dahl, R. E. (2012). Understanding adolescence as a period of social-affective engagement and goal flexibility. Nature Reviews Neuroscience, 13(9), 636-650. https://doi.org/10.1038/nrn3313

Crone, E. A., \& Konijn, E. A. (2018). Media use and brain development during adolescence. Nature 
Communications, 9(1), 588. https://doi.org/10.1038/s41467-018-03126-x

Dahl, R. E. (2004). Adolescent Brain Development: A Period of Vulnerabilities and Opportunities. Keynote Address. Annals of the New York Academy of Sciences, 1021(1), 1-22. https://doi.org/10.1196/annals.1308.001

Davidow, J. Y., Insel, C., \& Somerville, L. H. (2018). Adolescent Development of Value-Guided Goal Pursuit. In Trends in Cognitive Sciences (Vol. 22, Issue 8, pp. 725-736). Elsevier Ltd. https://doi.org/10.1016/j.tics.2018.05.003

Daw, N. D., Niv, Y., \& Dayan, P. (2005). Uncertainty-based competition between prefrontal and dorsolateral striatal systems for behavioral control. Nature Neuroscience, 8(12), 1704-1711. https://doi.org/10.1038/nn1560

Daw, N. D., O'Doherty, J. P., Dayan, P., Seymour, B., \& Dolan, R. J. (2006). Cortical substrates for exploratory decisions in humans. Nature, 441(7095), 876-879. https://doi.org/10.1038/nature04766

Dayan, P., \& Daw, N. D. (2008). Decision theory, reinforcement learning, and the brain. Cognitive, Affective, \& Behavioral Neuroscience, 8(4), 429-453. https://doi.org/10.3758/CABN.8.4.429 de Berker, A. O., Rutledge, R. B., Mathys, C., Marshall, L., Cross, G. F., Dolan, R. J., \& Bestmann, S. (2016). Computations of uncertainty mediate acute stress responses in humans. Nature Communications, 7, 10996. https://doi.org/10.1038/ncomms10996

De Martino, B., Bobadilla-Suarez, S., Nouguchi, T., Sharot, T., \& Love, B. C. (2017). Social Information Is Integrated into Value and Confidence Judgments According to Its Reliability. The Journal of Neuroscience : The Official Journal of the Society for Neuroscience, 37(25), 6066-6074. https://doi.org/10.1523/JNEUROSCI.3880-16.2017

Duell, N., \& Steinberg, L. (2019). Positive Risk Taking in Adolescence. Child Development Perspectives, 13(1), 48-52. https://doi.org/10.1111/cdep.12310

Egerton, A., Howes, O. D., Houle, S., McKenzie, K., Valmaggia, L. R., Bagby, M. R., Tseng, H. H., Bloomfield, M. A. P., Kenk, M., Bhattacharyya, S., Suridjan, I., Chaddock, C. A., Winton-Brown, T. T., Allen, P., Rusjan, P., Remington, G., Meyer-Lindenberg, A., McGuire, P. K., \& Mizrahi, R. (2017). Elevated Striatal Dopamine Function in Immigrants and Their Children: A Risk Mechanism for Psychosis. Schizophrenia Bulletin, 43(2), 293-301. https://doi.org/10.1093/schbul/sbw181

Engelmann, J. B., Moore, S., Monica Capra, C., \& Berns, G. S. (2012). Differential neurobiological effects of expert advice on risky choice in adolescents and adults. Social Cognitive and Affective Neuroscience, 7(5), 557-567. https://doi.org/10.1093/scan/nss050 
Ernst, M., Pine, D. S., \& Hardin, M. (2005). Triadic model of the neurobiology of motivated behavior in adolescence. Psychological Medicine, 36(03), 299. https://doi.org/10.1017/S0033291705005891

FeldmanHall, O., Dunsmoor, J. E., Kroes, M. C. W., Lackovic, S., \& Phelps, E. A. (2017). Associative Learning of Social Value in Dynamic Groups. Psychological Science, 28(8), 1160-1170. https://doi.org/10.1177/0956797617706394

FeldmanHall, O., Glimcher, P., Baker, A. L., \& Phelps, E. A. (2016). Emotion and decision-making under uncertainty: Physiological arousal predicts increased gambling during ambiguity but not risk. Journal of Experimental Psychology: General, 145(10), 1255-1262. https://doi.org/10.1037/xge0000205

FeldmanHall, O., \& Shenhav, A. (2019). Resolving uncertainty in a social world. Nature Human Behaviour, 3(5), 426-435. https://doi.org/10.1038/s41562-019-0590-x

Frankenhuis, W. E., \& Barto, A. G. (2019). Enriching behavioral ecology with reinforcement learning methods. Behavioural Processes, 161, 94-100. https://doi.org/10.1016/J.BEPROC.2018.01.008

Frankenhuis, W. E., \& Panchanathan, K. (2011). Individual Differences in Developmental Plasticity May Result From Stochastic Sampling. Perspectives on Psychological Science, 6(4), 336-347. https://doi.org/10.1177/1745691611412602

Frankenhuis, W. E., Panchanathan, K., \& Nettle, D. (2016). Cognition in harsh and unpredictable environments. In Current Opinion in Psychology (Vol. 7, pp. 76-80). Elsevier. https://doi.org/10.1016/j.copsyc.2015.08.011

Frey, R., Pedroni, A., Mata, R., Rieskamp, J., \& Hertwig, R. (2017). Risk preference shares the psychometric structure of major psychological traits. Science Advances, 3(10), e1701381. https://doi.org/10.1126/sciadv.1701381

Garbe, L., Rau, R., \& Toppe, T. (2020). Influence of perceived threat of Covid-19 and HEXACO personality traits on toilet paper stockpiling. PLOS ONE, 15(6), e0234232. https://doi.org/10.1371/journal.pone.0234232

Gardner, M., \& Steinberg, L. (2005). Peer Influence on Risk Taking, Risk Preference, and Risky Decision Making in Adolescence and Adulthood: An Experimental Study. Developmental Psychology, 41(4), 625-635. https://doi.org/10.1037/0012-1649.41.4.625

Gershman, S. J., Horvitz, E. J., \& Tenenbaum, J. B. (2015). Computational rationality: A converging paradigm for intelligence in brains, minds, and machines. In Science (Vol. 349, Issue 6245, pp. 273-278). American Association for the Advancement of Science. https://doi.org/10.1126/science.aac6076 
Giedd, J. N., Blumenthal, J., Jeffries, N. O., Castellanos, F. X., Liu, H., Zijdenbos, A., Paus, T., Evans, A. C., \& Rapoport, J. L. (1999). Brain development during childhood and adolescence: a longitudinal MRI study. Nature Neuroscience, 2(10), 861-863. https://doi.org/10.1038/13158

Gigerenzer, G., \& Gaissmaier, W. (2011). Heuristic Decision Making. Annual Review of Psychology, 62(1), 451-482. https://doi.org/10.1146/annurev-psych-120709-145346

Gopnik, A. (2020). Childhood as a solution to explore-exploit tensions. Philosophical Transactions of the Royal Society B: Biological Sciences, 375(1803), 20190502.

https://doi.org/10.1098/rstb.2019.0502

Gopnik, A., O’Grady, S., Lucas, C. G., Griffiths, T. L., Wente, A., Bridgers, S., Aboody, R., Fung, H., \& Dahl, R. E. (2017). Changes in cognitive flexibility and hypothesis search across human life history from childhood to adolescence to adulthood. Proceedings of the National Academy of Sciences of the United States of America, 114(30), 7892-7899.

https://doi.org/10.1073/pnas.1700811114

Gullone, E., Moore, S., Moss, S., \& Boyd, C. (2000). The Adolescent Risk-Taking Questionnaire. Journal of Adolescent Research, 15(2), 231-250. https://doi.org/10.1177/0743558400152003

Hertwig, R., Wulff, D. U., \& Mata, R. (2019). Three gaps and what they may mean for risk preference. Philosophical Transactions of the Royal Society B: Biological Sciences, 374(1766), 20180140. https://doi.org/10.1098/rstb.2018.0140

Hoppitt, W., \& Laland, K. N. (2013). Social learning: an introduction to mechanisms, methods, and models. Princeton University Press.

Johnston, L. D., O’Malley, P. M., Bachman, J. G., Miech, R. A., \& Schulenberg, J. E. (2014). Monitoring the Future national results on adolescent drug use: Overview of key findings, 2014.

Kirk, C. P., \& Rifkin, L. S. (2020). l'Il trade you diamonds for toilet paper: Consumer reacting, coping and adapting behaviors in the COVID-19 pandemic. Journal of Business Research, 117, 124-131. https://doi.org/10.1016/j.jbusres.2020.05.028

Knill, D. C., \& Pouget, A. (2004). The Bayesian brain: the role of uncertainty in neural coding and computation. Trends in Neurosciences, 27(12), 712-719. https://doi.org/10.1016/J.TINS.2004.10.007

Knoll, L. J., Magis-Weinberg, L., Speekenbrink, M., \& Blakemore, S.-J. (2015). Social Influence on Risk Perception During Adolescence. Psychological Science. https://doi.org/10.1177/0956797615569578

Latané, B. (1981). The psychology of social impact. American Psychologist, 36(4), 343-356. 
https://doi.org/10.1037/0003-066X.36.4.343

Laube, C., van den Bos, W., \& Fandakova, Y. (2020). The relationship between pubertal hormones and brain plasticity: Implications for cognitive training in adolescence. Developmental Cognitive Neuroscience, 100753. https://doi.org/10.1016/J.DCN.2020.100753

Luna, B., Paulsen, D. J., Padmanabhan, A., \& Geier, C. (2013). The Teenage Brain. Current Directions in Psychological Science, 22(2), 94-100. https://doi.org/10.1177/0963721413478416

Marković, D., \& Kiebel, S. J. (2016). Comparative Analysis of Behavioral Models for Adaptive Learning in Changing Environments. Frontiers in Computational Neuroscience, 10(April). https://doi.org/10.3389/fncom.2016.00033

Maslowsky, J., Owotomo, O., Huntley, E. D., \& Keating, D. (2019). Adolescent Risk Behavior: Differentiating Reasoned And Reactive Risk-taking. Journal of Youth and Adolescence, 48(2), 243-255. https://doi.org/10.1007/s10964-018-0978-3

Mathys, C., Daunizeau, J., Friston, K. J., \& Stephan, K. E. (2011). A bayesian foundation for individual learning under uncertainty. Frontiers in Human Neuroscience, 5, 39. https://doi.org/10.3389/fnhum.2011.00039

Mehlhorn, K., Newell, B. R., Todd, P. M., Lee, M. D., Morgan, K., Braithwaite, V. A., Hausmann, D., Fiedler, K., \& Gonzalez, C. (2015). Unpacking the exploration-exploitation tradeoff: A synthesis of human and animal literatures. Decision, 2(3), 191-215. https://doi.org/10.1037/dec0000033

Mills, K. L., Lalonde, F., Clasen, L. S., Giedd, J. N., \& Blakemore, S.-J. (2014). Developmental changes in the structure of the social brain in late childhood and adolescence. Social Cognitive and Affective Neuroscience, 9(1), 123-131. https://doi.org/10.1093/scan/nss113

Molleman, L., Kanngiesser, P., \& van den Bos, W. (2019). Social information use in adolescents: The impact of adults, peers and household composition. PLOS ONE, 14(11), e0225498. https://doi.org/10.1371/journal.pone.0225498

Molleman, L., Van Den Berg, P., \& Weissing, F. J. (2014). Consistent individual differences in human social learning strategies. Nature Communications, 5(1), 1-9. https://doi.org/10.1038/ncomms4570

Monahan, K. C., Steinberg, L., \& Cauffman, E. (2009). Affiliation with antisocial peers, susceptibility to peer influence, and antisocial behavior during the transition to adulthood. Developmental Psychology, 45(6), 1520-1530. https://doi.org/10.1037/a0017417

Morgan, T. J. H., \& Laland, K. N. (2012). The Biological Bases of Conformity. Frontiers in Neuroscience, 6(JUN), 87. https://doi.org/10.3389/fnins.2012.00087 
Morgan, Thomas J.H., Laland, K. N., \& Harris, P. L. (2015). The development of adaptive conformity in young children: effects of uncertainty and consensus. Developmental Science, 18(4), 511-524. https://doi.org/10.1111/desc.12231

Moutoussis, M., Dolan, R. J., \& Dayan, P. (2016). How People Use Social Information to Find out What to Want in the Paradigmatic Case of Inter-temporal Preferences. PLOS Computational Biology, 12(7), e1004965. https://doi.org/10.1371/journal.pcbi.1004965

Murty, V. P., Calabro, F., \& Luna, B. (2016). The role of experience in adolescent cognitive development: Integration of executive, memory, and mesolimbic systems. In Neuroscience and Biobehavioral Reviews (Vol. 70, pp. 46-58). Elsevier Ltd. https://doi.org/10.1016/j.neubiorev.2016.07.034

Nassar, M. R., Wilson, R. C., Heasly, B., \& Gold, J. I. (2010). An Approximately Bayesian Delta-Rule Model Explains the Dynamics of Belief Updating in a Changing Environment. Journal of Neuroscience, 30(37), 12366-12378. https://doi.org/10.1523/JNEUROSCI.0822-10.2010

Nelson, E. E., Jarcho, J. M., \& Guyer, A. E. (2016). Social re-orientation and brain development: An expanded and updated view. Developmental Cognitive Neuroscience, 17, 118-127. https://doi.org/10.1016/j.den.2015.12.008

Pickett, C. L., Gardner, W. L., \& Knowles, M. (2004). Getting a Cue: The Need to Belong and Enhanced Sensitivity to Social Cues. Personality and Social Psychology Bulletin, 30(9), 1095-1107. https://doi.org/10.1177/0146167203262085

Rahwan, I., Cebrian, M., Obradovich, N., Bongard, J., Bonnefon, J. F., Breazeal, C., Crandall, J. W., Christakis, N. A., Couzin, I. D., Jackson, M. O., Jennings, N. R., Kamar, E., Kloumann, I. M., Larochelle, H., Lazer, D., McElreath, R., Mislove, A., Parkes, D. C., Pentland, A. 'Sandy,' ... Wellman, M. (2019). Machine behaviour. In Nature (Vol. 568, Issue 7753, pp. 477-486). Nature Publishing Group. https://doi.org/10.1038/s41586-019-1138-y

Rivers, S. E., Reyna, V. F., \& Mills, B. (2008). Risk Taking Under the Influence: A Fuzzy-Trace Theory of Emotion in Adolescence. Developmental Review : DR, 28(1), 107-144. https://doi.org/10.1016/j.dr.2007.11.002

Rodman, A. M., Powers, K. E., \& Somerville, L. H. (2017). Development of self-protective biases in response to social evaluative feedback. Proceedings of the National Academy of Sciences of the United States of America, 114(50), 13158-13163. https://doi.org/10.1073/pnas.1712398114

Rodriguez Buritica, J. M., Heekeren, H. R., \& van den Bos, W. (2019). The computational basis of following advice in adolescents. Journal of Experimental Child Psychology, 180, 39-54. https://doi.org/10.1016/J.JECP.2018.11.019 
Romer, D., Lee, Y.-C., McDonald, C. C., \& Winston, F. K. (2014). Adolescence, Attention Allocation, and Driving Safety. Journal of Adolescent Health, 54(5), S6-S15.

https://doi.org/10.1016/J.JADOHEALTH.2013.10.202

Romer, D., Reyna, V. F., \& Satterthwaite, T. D. (2017). Beyond stereotypes of adolescent risk taking: Placing the adolescent brain in developmental context. In Developmental Cognitive Neuroscience. https://doi.org/10.1016/j.dcn.2017.07.007

Rosenbaum, G. M., Venkatraman, V., Steinberg, L., \& Chein, J. M. (2018). The influences of described and experienced information on adolescent risky decision making. Developmental Review, 47, 23-43. https://doi.org/10.1016/j.dr.2017.09.003

Sani, A., Lazaric, A., \& Munos, R. (2012). Risk-Aversion in Multi-armed Bandits. In Advances in Neural Information Processing Systems (Vol. 25).

Schulz, E., Wu, C. M., Ruggeri, A., \& Meder, B. (2019). Searching for Rewards Like a Child Means Less Generalization and More Directed Exploration. Psychological Science, 30(11), 1561-1572. https://doi.org/10.1177/0956797619863663

Segovia, G., Del Arco, A., De Blas, M., Garrido, P., \& Mora, F. (2010). Environmental enrichment increases the in vivo extracellular concentration of dopamine in the nucleus accumbens: $\mathrm{A}$ microdialysis study. Journal of Neural Transmission, 117(10), 1123-1130. https://doi.org/10.1007/s00702-010-0447-y

Sercombe, H. (2014). Risk, adaptation and the functional teenage brain. Brain and Cognition, 89, 6169. https://doi.org/10.1016/J.BANDC.2014.01.001

Shulman, E. P., Smith, A. R., Silva, K., Icenogle, G., Duell, N., Chein, J., \& Steinberg, L. (2016). The dual systems model: Review, reappraisal, and reaffirmation. Developmental Cognitive Neuroscience, 17, 103-117. https://doi.org/10.1016/J.DCN.2015.12.010

Shulman, E. P., Steinberg, L. D., \& Piquero, A. R. (2013). The Age-Crime Curve in Adolescence and Early Adulthood is Not Due to Age Differences in Economic Status. Journal of Youth and Adolescence, 42(6), 848-860. https://doi.org/10.1007/s10964-013-9950-4

Simon, H. A. (1956). Rational choice and the structure of the environment. Psychological Review, 63(2), 129-138. https://doi.org/10.1037/h0042769

Simon, H. A. (2019). The Sciences of the Artificial (3rd ed.). MIT press. https://mitpress.mit.edu/books/sciences-artificial

Somerville, L. H., Jones, R. M., Ruberry, E. J., Dyke, J. P., Glover, G., \& Casey, B. J. (2013a). The Medial Prefrontal Cortex and the Emergence of Self-Conscious Emotion in Adolescence. Psychological 
Science, 24(8), 1554-1562. https://doi.org/10.1177/0956797613475633

Somerville, L. H., Jones, R. M., Ruberry, E. J., Dyke, J. P., Glover, G., \& Casey, B. J. (2013b). The Medial Prefrontal Cortex and the Emergence of Self-Conscious Emotion in Adolescence. Psychological Science, 24(8), 1554-1562. https://doi.org/10.1177/0956797613475633

Somerville, L. H., Sasse, S. F., Garrad, M. C., Drysdale, A. T., Abi Akar, N., Insel, C., \& Wilson, R. C.

(2017). Charting the expansion of strategic exploratory behavior during adolescence. Journal of Experimental Psychology: General, 146(2), 155-164. https://doi.org/10.1037/xge0000250

Stamps, J. A., \& Frankenhuis, W. E. (2016). Bayesian Models of Development. In Trends in Ecology and Evolution (Vol. 31, Issue 4, pp. 260-268). Elsevier Ltd.

https://doi.org/10.1016/j.tree.2016.01.012

Steinberg, L. (2008). A social neuroscience perspective on adolescent risk-taking. Developmental Review. https://doi.org/10.1016/j.dr.2007.08.002

Steinberg, L., Icenogle, G., Shulman, E. P., Breiner, K., Chein, J., Bacchini, D., Chang, L., Chaudhary, N., Giunta, L. Di, Dodge, K. A., Fanti, K. A., Lansford, J. E., Malone, P. S., Oburu, P., Pastorelli, C., Skinner, A. T., Sorbring, E., Tapanya, S., Tirado, L. M. U., ... Takash, H. M. S. (2018). Around the world, adolescence is a time of heightened sensation seeking and immature self-regulation. Developmental Science, 21(2), e12532. https://doi.org/10.1111/desc.12532

Sutton, R. S., \& Barto, A. G. (2018). Reinforcement Learning. An Introduction (2nd ed.). MIT Press.

Telzer, E. H. (2016). Dopaminergic reward sensitivity can promote adolescent health: A new perspective on the mechanism of ventral striatum activation. Developmental Cognitive Neuroscience, 17, 57-67. https://doi.org/10.1016/J.DCN.2015.10.010

Telzer, E. H., van Hoorn, J., Rogers, C. R., \& Do, K. T. (2018). Social Influence on Positive Youth Development: A Developmental Neuroscience Perspective. Advances in Child Development and Behavior, 54, 215-258. https://doi.org/10.1016/BS.ACDB.2017.10.003

Tenenbaum, J. B., Kemp, C., Griffiths, T. L., \& Goodman, N. D. (2011). How to grow a mind: Statistics, structure, and abstraction. In Science (Vol. 331, Issue 6022, pp. 1279-1285). American Association for the Advancement of Science. https://doi.org/10.1126/science.1192788

Todd, P. M., \& Brighton, H. (2016). Building the Theory of Ecological Rationality. Minds and Machines, 26(1-2), 9-30. https://doi.org/10.1007/s11023-015-9371-0

Toelch, U., \& Dolan, R. J. (2015). Informational and Normative Influences in Conformity from a Neurocomputational Perspective. Trends in Cognitive Sciences, 19(10), 579-589. https://doi.org/10.1016/J.TICS.2015.07.007 
Toyokawa, W., Whalen, A., \& Laland, K. N. (2019). Social learning strategies regulate the wisdom and madness of interactive crowds. Nature Human Behaviour, 3(2), 183-193. https://doi.org/10.1038/s41562-018-0518-x

Tump, A. N., Pleskac, T. J., \& Kurvers, R. H. J. M. (2020). Wise or mad crowds? The cognitive mechanisms underlying information cascades. Science Advances, 6(29), eabb0266. https://doi.org/10.1126/sciadv.abb0266

van den Bos, W., \& Hertwig, R. (2017). Adolescents display distinctive tolerance to ambiguity and to uncertainty during risky decision making. Scientific Reports, 7(December 2016), 40962. https://doi.org/10.1038/srep40962

van den Bos, W., Laube, C., \& Hertwig, R. (2019). How the adaptive adolescent mind navigates uncertainty. In R. Hertwig, T. J. Pleskac, \& T. Pachur (Eds.), Taming Uncertainty (pp. 305-324). van Duijvenvoorde, A. C. K., Peters, S., Braams, B. R., \& Crone, E. A. (2016). What motivates adolescents? Neural responses to rewards and their influence on adolescents' risk taking, learning, and cognitive control. In Neuroscience and Biobehavioral Reviews. https://doi.org/10.1016/j.neubiorev.2016.06.037

Willoughby, T., Good, M., Adachi, P. J. C., Hamza, C., \& Tavernier, R. (2013). Examining the link between adolescent brain development and risk taking from a social-developmental perspective. Brain and Cognition, 83(3), 315-323. https://doi.org/10.1016/J.BANDC.2013.09.008

Wills, T. A., Vaccaro, D., \& McNamara, G. (1994). Novelty seeking, risk taking, and related constructs as predictors of adolescent substance use: An application of Cloninger's theory. Journal of Substance Abuse, 6(1), 1-20. https://doi.org/10.1016/S0899-3289(94)90039-6

Worthman, C. M., \& Trang, K. (2018). Dynamics of body time, social time and life history at adolescence. Nature, 554(7693), 451-457. https://doi.org/10.1038/nature25750

Wu, C. M., Schulz, E., Speekenbrink, M., Nelson, J. D., \& Meder, B. (2018). Generalization guides human exploration in vast decision spaces. In Nature Human Behaviour (Vol. 2, Issue 12, pp. 915-924). Nature Publishing Group. https://doi.org/10.1038/s41562-018-0467-4

Yeager, D. S., Dahl, R. E., \& Dweck, C. S. (2018). Why Interventions to Influence Adolescent Behavior Often Fail but Could Succeed. Perspectives on Psychological Science, 13(1), 101-122. https://doi.org/10.1177/1745691617722620

Zuckerman, M., Eysenck, S. B., \& Eysenck, H. J. (1978). Sensation seeking in England and America: Cross-cultural, age, and sex comparisons. Journal of Consulting and Clinical Psychology, 46(1), 139-149. https://doi.org/10.1037/0022-006X.46.1.139 
